Article

\title{
Trends and Possible Future Developments in Global Forest-Product Markets-Implications for the Swedish Forest Sector
}

\author{
Ragnar Jonsson \\ Southern Swedish Forest Research Centre, SLU, P.O. Box 49, SE-230 53 Alnarp, Sweden; \\ E-Mail: Ragnar.Jonsson@ slu.se; Tel.: +46-40-415-186; Fax: +46-40-462-325
}

Received: 30 November 2010 / Accepted: 18 January 2011 / Published: 20 January 2011

\begin{abstract}
This paper analyzes trends and possible future developments in global wood-product markets and discusses implications for the Swedish forest sector. Four possible futures, or scenarios, are considered, based on qualitative scenario analysis. The scenarios are distinguished principally by divergent futures with respect to two highly influential factors driving change in global wood-product markets, whose future development is unpredictable. These so-called critical uncertainties were found to be degrees to which: (i) current patterns of globalization will continue, or be replaced by regionalism, and (ii) concern about the environment, particularly climate change, related policy initiatives and customer preferences, will materialize. The overall future of the Swedish solid wood-product industry looks bright, irrespective of which of the four possible futures occurs, provided it accommodates the expected growth in demand for factory-made, energy-efficient construction components. The prospects for the pulp and paper industry in Sweden appear more ambiguous. Globalization is increasingly shifting production and consumption to the Southern hemisphere, adversely affecting employment and forest owners in Sweden. Further, technical progress in information and communication technology (ICT) is expected to lead to drastic reductions in demand for newsprint and printing paper. Chemical pulp producers may profit from a growing bio-energy industry, since they could manufacture new, high-value products in integrated bio-refineries. Mechanical pulp producers cannot do this, however, and might suffer from higher prices for raw materials and electricity.
\end{abstract}


Keywords: future; global; wood products; scenario analysis; critical uncertainties; pulp and paper; globalization; construction component; ICT

\section{Introduction}

The Swedish forest industry accounts for 15 to $20 \%$ of the country's total industrial investment, employing around 180,000 people nationally (including indirect employment in sectors that supply goods and services to the forest industry), more than a quarter of total industrial employment [1]. Sweden is also a major force in global forest-product markets, as it is the world's second largest exporter of paper, pulp and sawn timber [2]. The Swedish forest industry is highly export-oriented and export-dependent, e.g., $89 \%$ of the paper produced in 2009 was exported [3].

Overall, it may be concluded that developments in global forest-product markets are likely to have far-reaching implications for the Swedish forest sector, affecting land-use, investments in forest management, employment and regional development. The objectives of this paper are to present and analyze possible future developments in global forest-product markets and discuss the overall implications of these developments for the Swedish forest sector, with a time horizon of about forty years from now (i.e., around 2050).

After presenting trends and possible future developments, with regard to major drivers of change in global forest-product markets, different methods for futures studies are briefly reviewed, focusing particularly on scenario analysis. Scenario analysis is then applied to address four alternative futures, differing with respect to developments in global wood-product markets and resulting demand pressure on the Swedish forest resource. The paper ends by discussing the findings and presenting conclusions regarding their implications for the Swedish forest industry.

The focus of this study is on commodities made from woody biomass, referred to as wood products or forest products throughout the paper.

\section{Drivers of Change in Global Forest-Product Markets}

Assessment of possible future developments in global wood-product markets requires understanding of how factors driving change in these markets are likely to evolve. Factors frequently cited as drivers of change with regard to long-term global demand for wood products are: economic development; demographics; scientific and technological developments; globalization; global climate change; policies, regulations and customer preferences linked to climate change; environmental policies and regulations other than those linked to climate change (e.g., [4-7]).

\subsection{Economic Development}

Economic growth, measured by the rate of change in gross domestic product (GDP), is generally associated with growing demand for products and services, including wood products. According to neo-classical growth theory, economic growth is driven by growth in population (i.e., labor supply), capital and technological change [8,9]. Due to diminishing returns to capital, and labor increases, 
economies will eventually reach a point (steady state) at which no new increase in production factors will create economic growth. In neo-classical growth theory, the process by which the economy continues to grow is exogenous and represents the creation of new technology [8,9]. Endogenous growth theory maintains that the development of new forms of technology is driven by enhancement of a nation's human capital [10]. Further, as personal incomes increase, individuals tend to spend a higher proportion of their income on activities that are largely personal pleasures, and less on basic needs. Hence, with increasing incomes, countries move up the hierarchy towards a pattern of demand that focuses more on less basic needs [11].

While developed economies accounted for most of global GDP in the period 1970-2005, the rapid growth of developing economies, especially in Asia, is expected to swing the balance significantly in the future. The rate of economic growth in Western Europe, the most important export market for Swedish forest products, is much lower than in developing regions, and is predicted to slow further. For example, real GDP growth in Germany is projected to be slightly less than two percent per annum during the period from 2010 until 2020, and to decrease to about 1.3\% during the period from 2020 to 2030 [12]. The global demand for forest products is thus expected to continue to grow, but mainly in China, India, Brazil, and other developing countries, in line with their growth in population and income. However, most Western European countries have a research and development expenditure of more than two percent of GDP [13]. Hence, high investments in science and technology in Europe could favor the transition to a knowledge-based post-industrial "green" economy, based on sustainable use of resources [7].

\subsection{Demographics}

Demographics affect forest-product markets in several ways. First of all, population increases can result in economic growth and increased demand, as mentioned above. A large population also provides a large domestic market for the economy. Nevertheless, rapid population growth, aside from potential feeding problems, also imposes constraints on the development of savings (and thus, subsequently, on investments), as it leads to more dependent children [14,15]. The world's total population is projected to stabilize at slightly over nine billion in 2050 , whereas total population in Europe is expected to decrease from 730 million in 2005 to around 660 million in 2050, according to UN medium fertility forecasts [16]. This projected fall in population could partly explain the expected slow economic growth in Europe, although economic welfare in the sense of GDP per capita would increase.

In terms of housing demand, the number of households is more important than population size [17]. The number of households in Europe is projected to increase by $20 \%$ from 2005 to 2030, as households are becoming smaller, implying that demand for housing, furniture and (hence) sawnwood and wood-based panel products will continue to rise [18].

In addition to the total population and number of households, the degree of urbanization influences forest-product markets. Increased urbanization tends to increase a society's demand for non-wood forest products and services, relative to wood products [4], while at the same time reducing wood-product harvests, as forest management is affected far beyond the urban boundary [19,20]. The effect on net demand for wood products is thus equivocal. Further, by reducing the rural workforce, 
increased urbanization leads to difficulties in attracting people to work in forestry [21], thereby putting upward pressure on labor costs. Urbanization is expected to increase further in Sweden and Europe as well as globally [16].

Changes in the age structure of the population also have potentially important effects on forest-product markets. As shown in Figure 1, the population is clearly ageing, globally as well as in Europe and Sweden. On the demand side, the proportion of the population older than 75 years has been shown to have a significant negative effect on residential construction volumes, due to the increasing burden on the working population [22]. An ageing population also has supply effects, as it entails a shrinking workforce, thereby accelerates technological progress in the construction industry in order to reduce labor costs, i.e., more construction components will be factory-made [23].

Figure 1. Historical, current and projected proportions (percent) of Swedish, European and global populations aged 65 years or more. Source: UN medium fertility variant [16].

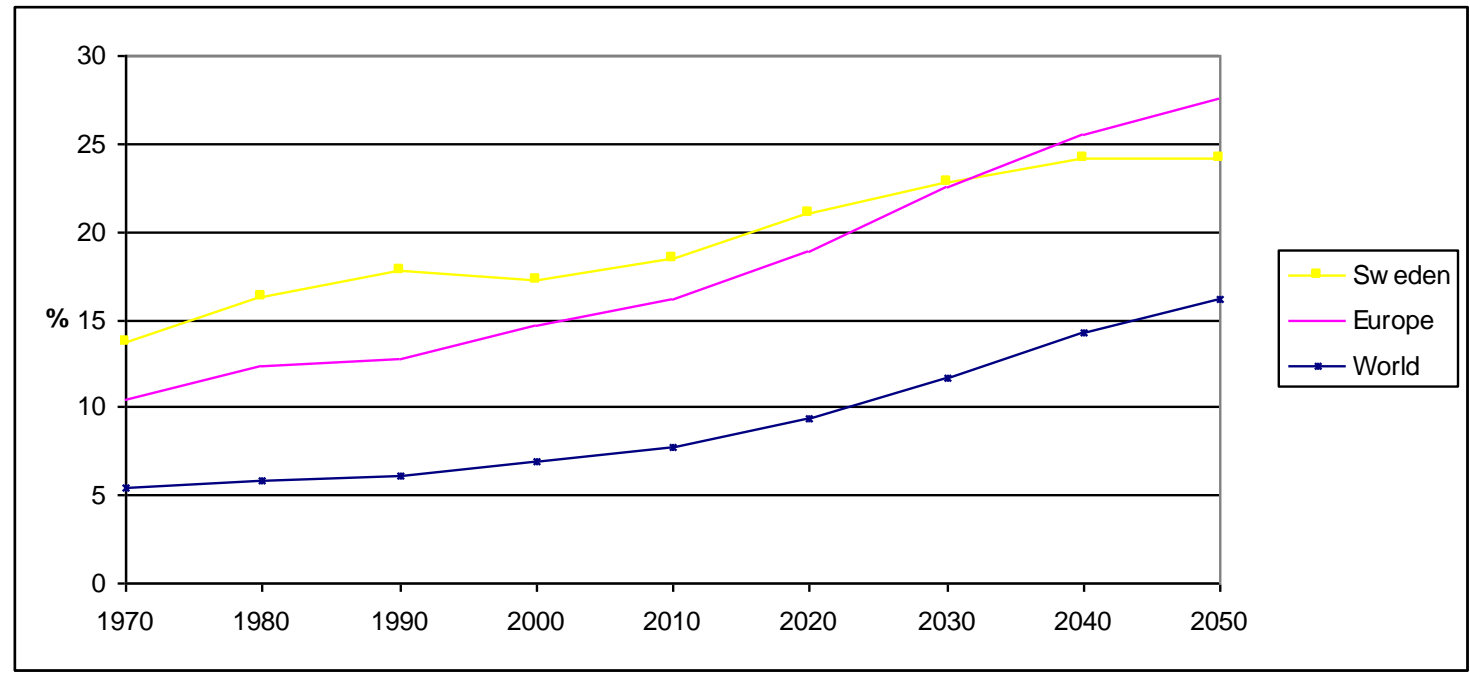

\subsection{Scientific and Technological Developments}

Scientific and technological developments in silviculture, forest management, harvesting, transport and processing of wood products, and information technology, are expected to be most relevant for forest-product markets [4,7].

Research within the areas of forest management and silviculture has focused on planted forests and short-rotation species. Research here aims primarily to identify ways to increase forest growth rates and wood quality as well as the ability of forests to withstand adverse environmental conditions, pests and diseases. This focus on fast-growing species relates to demand from the pulp and paper industry and reconstituted wood-panel producers. Enormous productivity gains have been obtained for species such as eucalyptus and tropical pines [7]. New possibilities, though controversial, for improving production and quality are provided by research in gene transfer technology and tree genomics; see, for instance, Evans and Turnbull [24]. These developments all contribute to an increase in the supply of roundwood for wood-processing industries.

Technological improvements in wood processing have made the use of small-dimension sawlogs possible, hence, in a number of northern countries, notably Finland, Sweden and Canada, the 
proportion of pulpwood production in total industrial roundwood production has fallen in recent decades. Another effect of these improvements has been an increase in the production of wood chips from sawmills, used in the production of reconstituted wood panels, wood pulp, or for bio-energy [25]. Research efforts, mainly in Europe and North America, aim at transforming pulp and paper units into bio-refineries, i.e., integrated industries that produce ethanol, starch, organic acids, polymers, oleochemicals, bioplastics and various food and feed ingredients, from wood-processing residues. These bio-refineries could be key features in the creation of a "green economy", by reducing dependence on fossil fuels [26]. This development should also benefit the profitability of the pulp and paper industry, since the primary goal of converting a given chemical pulp mill into an integrated bio-refinery is to create more value from the bio-based raw material provided by the forestry sector [27]. Large-scale establishment of integrated bio-refineries should thus increase the use of forest raw materials while at the same time potentially increasing the efficiency of raw material use. In the future, nanotechnology is expected to result in further advances in material and energy efficiency, from production of raw materials to composite and paper products $[28,29]$. The increased efficiency this entails should dampen global demand for wood fiber. In addition to efficiency gains, advances in nanotechnology are expected to enhance properties of wood products and lead to the creation of new materials, e.g., by injecting ceramic nanoparticles into wood to improve their mechanical properties and fire resistance, and new construction materials based on wood fiber/plastic composites [28].

Progress in information and communication technology (ICT) has already had a fundamental impact on the paper market in the USA. Hence, long-run income elasticity (the responsiveness of demand to income changes) for newsprint consumption turned negative after 1987 [30]. Econometric analyses of historical data for West European countries have not indicated a general structural shift in newsprint consumption [31], but recent studies indicate that the situation is changing. In addition, the market for office paper seems to have restructured in recent years; growth in consumption of office paper has slowed markedly, ceased altogether, or even started to fall in some OECD countries. As for newsprint, the change has been most noticeable in North America [32]. The development of electronic ICT and ensuing decrease in the demand for paper implies that less forest resources will be needed for pulp production [33].

\subsection{Globalization}

For the forest sector, the principal effect of globalization has been reduced transport costs, which have led to increased forest-product trade and the creation of a truly global market for forest products [4]. Globalization has reduced the importance of forest resources for the forest industry, and development has been driven predominantly by labor costs, levels of research and technology, and access to capital [25]. Intensively managed forest plantations are increasingly replacing natural forests as the raw material resource. These changes eliminate the traditional ties between forest processing and locations with abundant natural forests [34]. Hence, forest industry functions have become spatially separated, i.e., companies now utilize materials from various sources, and consequently can site manufacturing plants at different locations along the value chain, from the forest to the consumer [4].

The relative advantage in wood production is thus moving away from countries with large forest resources in the northern hemisphere toward countries where trees grow quickly; the future supply of 
wood and fiber will increasingly depend on the availability of land for forest plantations, and their environmental and social costs [25]. For countries like Sweden and Finland, succeeding in global competition on a domestic basis alone is not possible. Consequently, Nordic forest companies are expected to continue to invest in forest plantations and pulp mills in South America, whereas paper machines will be located in Asia, where demand is growing most rapidly [35].

These developments will, of course, adversely affect employment in the Swedish forest-product industry. The implications for Northern Sweden are particularly serious; here raw-material-based industries, such as forest industries, often provide the only means of employment [36]. Swedish forest owners will also face negative consequences, as cheap hardwood pulp from the southern hemisphere will exert downward pressure on the price of Swedish softwood pulp. The Swedish sawmill industry, however, should not face the same direct threat, since the forest expansion in the southern hemisphere is mainly focused on pulp and paper production [25]. Further globalization could also conceivably be halted by dramatically increasing transports costs, or by major international conflicts disrupting global trade, arising for example from competition for natural resources in the Arctic region [37].

\subsection{Global Climate Change}

Anticipated changes in the world's climate are likely to affect, substantially, every aspect of the environment and the economy [6]. Inter alia, expected changes in temperature and precipitation patterns will probably have strong direct effects on both natural and modified forests [5], affecting both the growth rates and optimal locations for tree species [38].

Hence, climate change is expected to improve forest productivity on a global scale while increasing regional variability, thereby complicating the relationship between supply and asset appreciation [6]. In boreal regions, such as Sweden, elevated atmospheric $\mathrm{CO}_{2}$ concentrations accompanied by warming and longer growth seasons are generally expected to increase timber production over the coming century, by inducing a polarward shift of the most important forestry species and accelerating vegetation growth [39-42]. These flow effects could have major economic implications in the long term, e.g., global timber harvests could be six percent greater in 2050 than they might have been without warming [43]. In the shorter term, up to 2025, timber harvest levels are not expected to change substantially in boreal forests [38].

However, stock effects, i.e., changes in frequencies or the nature of disturbances, such as forest fires, pest infestations, severe drought or windthrow, may have potentially important impacts in the near and medium terms [38]. Notably, increased frequencies of extreme events such as strong winds, droughts, etc., aggravated by insect outbreaks and wildfires, can cause massive losses to commercial forestry [5]. An obvious example is the mountain pine beetle infestation in Western Canada. Ensuing salvage logging is projected to increase short-term timber supply and reduce prices, whereas longer term timber supply will decrease [44-46].

Modeling results suggest that the decline in the global importance of boreal forests, as global timber harvests shift towards subtropical plantation regions, will continue over the medium term, as impacts of lower world prices outweigh benefits of rising forest productivity in boreal regions $[44,45]$. An important aspect to bear in mind in this context is that no large differences in global warming between different greenhouse gases (GHG) emission scenarios are foreseen until at least 2050 [47], and this 
should be valid even if climate changes are ultimately greater than expected, due to the inherent inertia of the climate system (e.g., [48]).

\subsection{Policies, Regulations and Customer Preferences Linked to Climate Change}

Policies aimed at mitigating climate-change can affect forest-product markets in various ways. One is by encouraging use of wood products instead of other materials that yield more GHG emissions during the course of their production, subsequent use and disposal [49]. As an example, public policies promoting the use of energy-efficient, renewable construction materials (e.g., the Code for Sustainable Homes in the UK [50]) could boost global demand for construction timber. However, the way in which green building standards are formulated will greatly influence the strength of preferences for sustainable wood products over competing materials, based on lifecycle carbon emissions [6].

Public policies also affect global forest-product markets by influencing the development and use of bio-energy and bio-fuel, e.g., in 2007 the European Commission set a target of $20 \%$ for the total energy used in the EU, and a mandatory target of $10 \%$ for the energy used in petrol and diesel transport, to be from renewable sources by 2020 [51]. These targets have already stimulated increasing demand for wood as an energy source, particularly for wood pellets as a substitute for fossil fuel in small-scale heating and electricity production [52]. Bio-energy may provide opportunities for new markets, but will also pose challenges to traditional forest-product manufacturers, by increasing costs of raw materials and thereby reducing competitiveness with substitute materials [6,53]. Hence, the wood-based panel industry will face more competition for all its raw materials, i.e., slabs, chips, sawdust and roundwood, while at the same time having no secondary products to feed into the energy markets. Sawmills, on the other hand, should mainly benefit from the development of wood-based bio-energy markets, as sawlogs have high value and less competition from energy uses, and should attract higher prices for secondary products (slabs, chips, and sawdust) demanded by bio-energy markets. Chemical pulp producers will face increased competition for raw materials, but may also profit from a growing bio-energy industry since, as already mentioned, they could manufacture new, high-value products in integrated bio-refineries. Mechanical pulp producers cannot do this, however, and will suffer from higher prices for raw materials and electricity [53]. Landowners will benefit from the development of bio-energy, as a result of increased competition, and hence higher prices, for wood raw materials [54]. However, bio-energy and bio-fuel can also be produced from annual plants, thus increasing the competition with forests for land-use [6].

Mitigation policies involving forest-based carbon sequestration raise complex issues, hence their effects on forest-product markets have high degrees of uncertainty. Increasing the standing inventory of forest biomass implies a greater sequestration of carbon. This can be achieved by converting non-forest land into forests, i.e., by afforestation, reducing deforestation, and/or by appropriate adjustment of forest management and silvicultural regimes. Management activities promoting increased growth and volume will typically enhance carbon sequestration [55]. For example, fertilization could increase carbon storage [56-59]. Further, reducing and/or delaying harvests (i.e., lengthening rotations) increases the amount of carbon sequestered [60-62]. A model of global forest carbon sequestration suggests that while in the short term global timber supply declines as landowners lengthen rotations, in the longer term (up to 2050 and beyond) the combination of expanding forest area and longer rotations 
will lead to a dramatic increase in timber supply and subsequent reductions in global timber prices [46]. Reducing tropical deforestation is perhaps the most efficient approach for carbon sequestration, since: deforestation in the tropics is still proceeding at a substantial rate [63], tropical forests are more efficient engines of carbon sequestration, and opportunity costs are lower than for temperate forests [64].

De facto climate change, as well as the notion of climate change, is expected to lead to increased consumer preferences for "green products", particularly in the construction sector. Preferences are also expected to shift from fossil fuels to bio-energy and bio-fuel due to rising energy prices [5]. As climate-change benefits of sustainable forest products are not widely understood, there is an opportunity for the industry to improve its consumer relations [6]; paper and wood have the lowest energy consumption and the lowest carbon dioxide emissions of any commonly used packaging or building materials [65].

\subsection{Environmental Policies and Regulations}

Environmental policies and regulations have a potentially strong impact on wood supply as well as the production, consumption and trade of wood products. Policy experts expect environmental policies and regulations to place increasing emphasis in the future on nature conservation, the promotion of biodiversity, and nature-oriented forest management [66]. For instance, various studies have shown that the natural environment, biodiversity and the protective functions of forests are widely recognized and highly valued by the European public [67]. Accordingly, the German government intends to increase the proportion of unmanaged forest area in Germany to five percent by 2020 [68].

Greater emphasis on nature conservation and promotion of biodiversity is expected to reduce wood removals and production in Europe [66]. Estimates of the impacts of biological and landscape diversity protection on wood supply in Europe indicate that it may reduce potential harvests by about 70 million cubic meters in protected areas [69]. Policy measures promoting nature-oriented forest management, including elimination or reduction of clear-cutting in favor of more selective harvesting, will presumably also lead to a reduction in wood supply [66].

\section{Future studies}

The purpose of futures analysis is to create or strengthen awareness of the future by offering alternative prospects for the future, and its value is in facilitating the planning and consideration of new possibilities rather than in forecasting accuracy [70]. The methods applied in future studies encompass, among others, qualitative and quantitative trend analysis, simulation modeling, Delphi analysis, and scenario analysis [71].

Qualitative trend analysis involves identifying leading trend indicators that are presumed to determine future developments. In quantitative trend extrapolation, past data are projected into the future. Quantitative trend analyses are generally most relevant for short time horizons, e.g., one to five years [72]. Different types of trend analyses all assume that the future will, to a large extent, be a continuation of the past, i.e., that certain phenomena are likely to persist $[73,74]$.

Simulation modeling is a quantitative approach to futuring, where mathematical relationships are used to imitate a system; these relationships are then built into an internally consistent set of algorithms 
used mainly for forecasting environmental impacts [75]. Simulation models are frequently used for mid-range time horizons, when there is still considerable predictability about the future, but also considerable uncertainty [76].

Delphi analysis is a qualitative future studies method. It is a consensus-based group process for systematically soliciting (usually using a set of sequential questionnaires), collating, and refining a set of informed judgments regarding issues determined by a small number of variables. Delphi studies work best when dealing with relatively short-term futures [77], and are most suitable for exploring issues involving both social values and science [78].

Scenario analysis involves developing alternative visions of the future. A key aim of scenariobuilding is to extend thinking in terms of length of time, e.g., beyond five to ten years into the future, and breadth, e.g., across a range of possible futures [72]. Raskin and Kemp-Benedict [79] maintain that the long-term future cannot be extrapolated or predicted because of three types of indeterminacy: ignorance (insufficient information on the current state of the system and the forces governing its dynamics), surprise (possibilities for novelty, surprise and emergent phenomena making accurate prediction impossible) and volition (the future is unknowable because it is subject to human choices that have not yet been made). Scenarios describing futures that could be, rather than futures that will be $[80,81]$, take over when forecasting capabilities decline, i.e., uncertainties start to dominate over predetermined processes [82].

There are various approaches for developing scenarios, ranging from quantitative to qualitative, trend versus peripheral (i.e., unlikely and extreme events) [83], and from informal imaginative exercises by a single individual to a systematic group process [72]. Schwartz [84] recommends a structured approach, as follows:

1. Define the topic/problem and focus of the scenario analysis.

2. Identify and review the key factors/environmental influences on the topic (drivers).

3. Identify the critical uncertainties.

4. Define scenario logics.

5. Create/flesh out the scenarios.

6. Assess implications.

7. Propose actions and policy directions.

The driving forces, or causal factors, are classified as either constant (unlikely to change), predetermined (predictable change) or uncertain [85]. An important step in scenario creation, according to Schwartz's approach [84], is to distinguish the critical uncertainties, as this step defines the following scenarios. Hence, two general areas of critical uncertainty, i.e., two highly important and unpredictable (uncertain) clusters/factors, are identified [82,84]. The critical uncertainties could be individual drivers, but one could also define more complex uncertainties in terms of groups of drivers [82]. The ends of the axes represent extreme, contrasting, outcomes for the critical uncertainties (see Figure 2). The drivers that are not used in defining the uncertainties can still be used in the descriptions of the scenarios. For instance, drivers that have a high predictability could be used in all scenarios to provide internal consistency. Each generated scenario is characterized by specific states or outcomes of the two critical uncertainties and the other drivers, e.g., low A and high B characterize scenario 2 in Figure 2. In creating and fleshing out the scenarios, care must be taken to make them 
internally consistent, i.e., main trends and outcomes of key drivers that can logically co-exist [86,87]. It is important, however, to remember that no single set of scenarios is "correct"; the value of the scenarios lies in the strategic discussions they generate [82].

Figure 2. From drivers to critical uncertainties and scenarios. From Postma and Liebl [82].

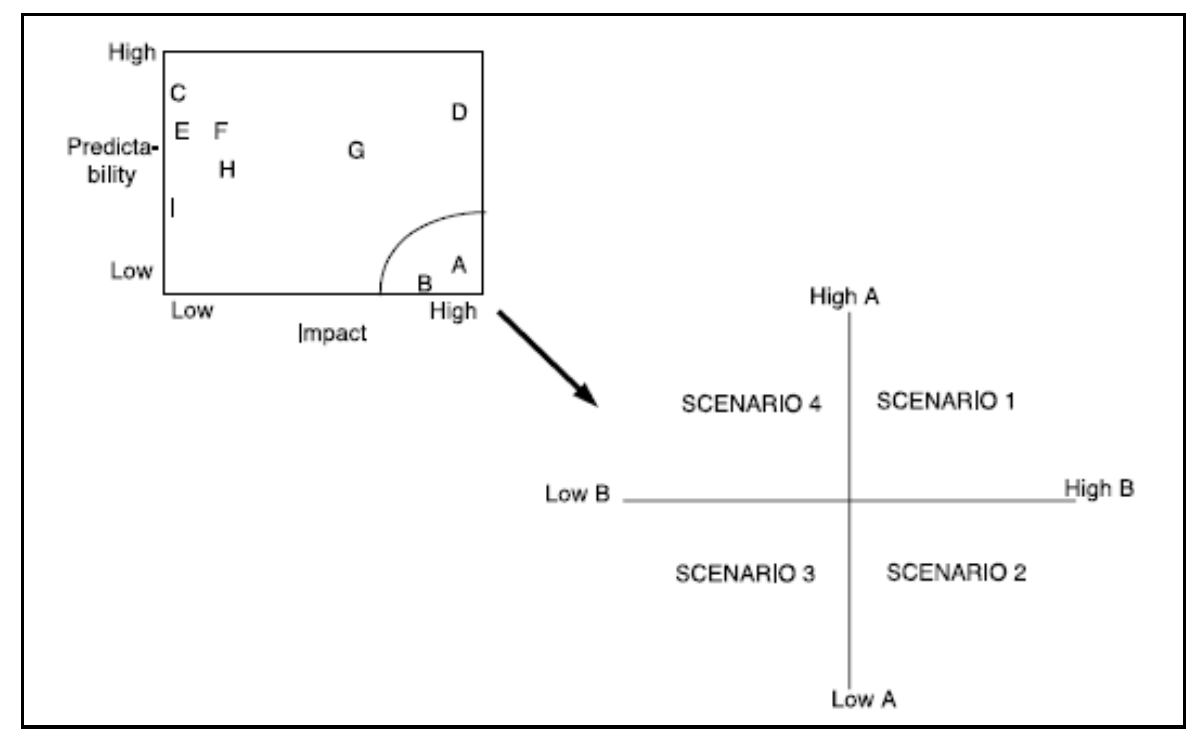

\section{Methods}

All data cited, analyzed and discussed in this paper are from secondary sources such as scientific journals, trade papers, official statistics, government reports and studies. The futuring approach used here is scenario analysis; the main rationale for this choice is the rather long-term horizon (up to 2050), entailing increasing uncertainties. The scenario development and analysis in this instance is qualitative in nature, based on discussions and deliberations. The approach follows steps one to six described in the methods section, i.e., no comprehensive directions for policy are suggested.

The scenarios are defined by divergent futures associated with two critical uncertainties: the degrees to which (i) current patterns of globalization will continue or be replaced by regionalism, and (ii) concern about the environment, particularly climate change, related policy initiatives and customer preferences, will materialize. The second of the critical uncertainties is composed of the two drivers Policies, regulations and customer preferences linked to climate change and Environmental policies and regulations. The underlying assumption here is that concern for the environment and concern for the climate are linked.

Both of the critical uncertainties defined are considered to be of paramount importance for global forest-product markets and also subject to considerable unpredictability, unlike (for instance) demographic developments. The main reason for choosing Policies, regulations and customer preferences linked to climate change rather than Global climate change is that up until 2050 large differences in global warming are not expected, irrespective of emission scenario [47]. Hence, no large differences in the effects of climate change between different scenarios are foreseen, making Global climate change less suitable for defining scenarios. This is not to say that climate change will not have profound effects on forest conditions and forest-product markets in the near and medium term, rather that climate change in this analysis is incorporated in the scenario descriptions. 


\section{Results: Scenario Analysis-Four Alternative Futures}

Below, four scenarios for the developments in global forest-product markets and their implications for the Swedish forest sector are presented. The scenarios are distinguished principally by divergent futures with regard to the two critical uncertainties mentioned in the methods section (see Figure 3 ).

Figure 3. The scenarios.

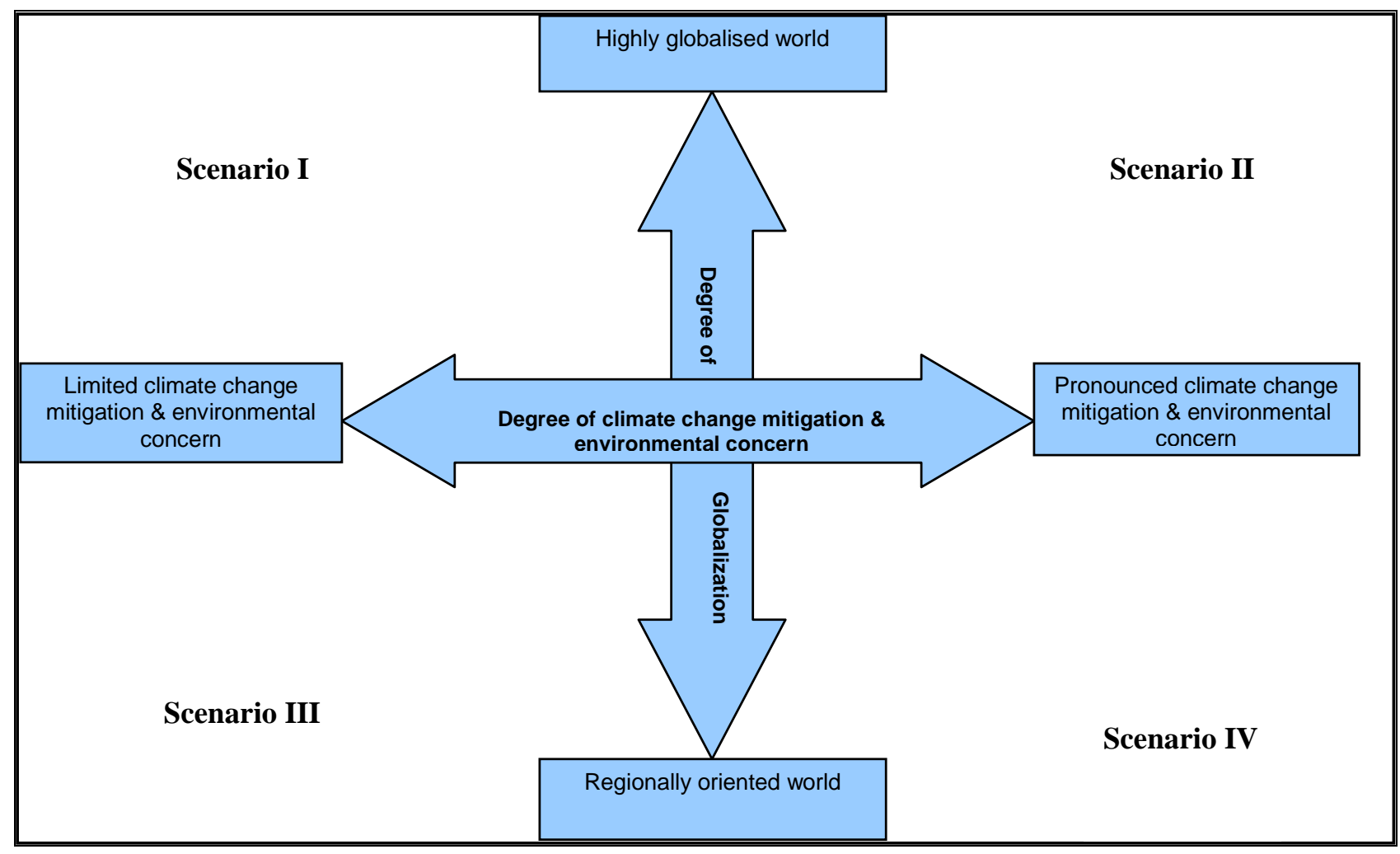

I. This scenario is characterized by unabated globalization, rapid global technological progress and economic growth, little in the way of climate-change mitigation efforts, low environmental concern, and relatively low energy and transport costs. The global population has stabilized in 2050, while the population in Europe is declining and ageing. Due to rapid economic growth and huge populations, China and India are the main consumers of wood products. Bio-energy markets have developed modestly globally; even in the European Union (EU) the bio-energy targets for 2020 were reached by only a handful of the member countries. Recycling rates have not risen above today's levels. Cheap wood raw materials, as well as commodities, are imported to the EU, leading to continued falls in real prices. As a result, annual harvest levels in the EU have decreased and there is little investment in forest management. Further, annual harvest levels fluctuate more than today as a result of climate-related calamities and ensuing salvage logging, i.e., climate-change stock effects are evident. The solid wood-product industry in Sweden and Europe in general, having seen considerable structural rationalizations, has invested heavily in technical development; large, integrated production units now supply high-tech timber construction components, including composites produced nanotechnologically, to meet the demands of a highly industrialized 
construction industry (partly due to a shrinking workforce). The Nordic pulp and paper industry has seen further mergers. Cheap wood fiber has increased profits, but the bulk of pulp and paper is produced in the Southern hemisphere. The pulp and paper industry remaining in Sweden focuses on supplying value-added products. Continued expansion of electronic ICT has resulted in dramatic decreases in newsprint and office paper production, consumption, and exports. As a consequence, less forest resources are needed for pulp production in Sweden. Overall, the demand for Swedish wood raw materials is relatively low, and the total supply of wood fiber in Sweden has not increased compared to today's level. Employment in the Swedish forest sector is lower than today; a result of technological progress driven by continued urbanization, a declining work force in general (driving up the cost of labor), and extensive forest management. Due to falling real wood prices, the real prices for forest land have increased modestly.

II. As in scenario I, scenario II is characterized by a high degree of globalization accompanied by rapid technological development and economic growth (albeit slower than in scenario I). In scenario II, however, climate-change mitigation efforts are prominent worldwide. There is also a high degree of environmental concern amongst the public as well as policy-makers. Energy and transport costs are higher than in scenario I, but not dramatically higher, due to continuous and successful substitution of bio-energy and bio-fuels, including those from woody biomass, for fossil fuels. The global population has stabilized, while the European population is declining and ageing. Urbanization in Sweden and a number of other European countries has halted; a growing number of people want to live close to nature. Plantation forests in the Southern hemisphere are being increasingly used to produce bio-energy feedstocks, and are at the same time facing increased competition from alternative land-uses; agricultural production and non-wood sources of bio-fuel. Real prices of forest products have increased worldwide compared to today's levels. Global recycling rates have risen dramatically. Despite reduced imports of wood raw materials and the fact that forest productivity has generally risen, harvest levels in the EU are not, on average, higher than current levels, due to greater emphasis on nature conservation and biodiversity. Forests are also used increasingly as carbon sinks, resulting in reduced and/or delayed harvests. As mitigation efforts have only slowed down climate change marginally as yet, harvest levels fluctuate more than today due to calamities induced by climatic changes. Large production units of sawmills integrated with chemical pulp and paper units in bio-refineries benefit from increasing demand for energy-efficient, renewable construction materials (including composites produced nanotechnologically), bio-fuel and bioplastics. Pure wood-based panel producers, on the other hand, have disappeared due to intense competition for all its raw materials from the bio-energy sector. As a result of continued expansion of electronic media, newsprint and office paper production, consumption, and exports have all but disappeared. Only chemical pulp and paper units that have been converted into bio-refineries are surviving (mechanical pulp production has lost viability and collapsed in Sweden and the rest of Europe due to price increases for raw materials and energy, driven by the growing bio-energy industry, and the lack of compensatory advantages). Overall, less forest resources are needed for pulp production in Sweden. The 
annual harvest level in Sweden has increased significantly compared to today's level, despite a strong focus on environmental issues, due to an elevated net global demand for wood fiber, not least from the energy sector. Hence, forests exempt from conservation are managed intensively and rotations have been shortened in these production forests. However, forests with low wood-production potential are managed increasingly for non-wood ecosystem services (eco-tourism, as well as large-scale industrialized berry picking, has increased considerably) and as carbon sinks. The property rights for non-wood ecosystem services, e.g., berry-picking, have been strengthened at the expense of public access. In spite of technological improvements, employment in the Swedish forest sector is higher than today; a result of the elevated demand for wood and the growth of non-wood ecosystem services. Forest owners in Sweden have benefited from the development of bio-energy and the resulting increased competition for, and hence prices of, wood raw materials. The real value of forest land is significantly higher than today.

III. In this scenario, increases in international conflicts over natural resources have resulted in a shift away from free trade and globalization, to a regime of strong regional trading blocs. The EU has consolidated its influence, but there has been no further enlargement of the union. The scenario is further characterized by little climate-change mitigation, low environmental concern, and intermediate levels of economic growth and technological progress. Energy and transport costs are higher than in Scenarios I and II. Global population has stabilized, while the European population has started to decline. Though climate-change mitigation efforts are rather limited, the bio-energy markets in the EU have developed dramatically, as a result of an urge (and need) to reduce dependence on fossil fuel imports. EU recycling rates are considerably higher than today, as imports of raw materials have decreased sharply. Greatly reduced wood imports to the EU, in combination with the high demand for wood in construction and for energy purposes, has increased the demand for European wood. As a result, harvest levels in the EU are considerably higher than today and forests are managed intensively. However, harvest levels fluctuate widely, as a result of calamities caused by climate change. Real prices of forest products have increased compared to current levels. Sawmills in Sweden and the rest of Europe, often integrated with chemical pulp and paper units in bio-refineries, are in a favorable position due to the increased demand for energy-efficient, renewable construction materials. The wood-based panels industry, on the other hand, is in dire straits due to intense competition for all its raw materials from the bio-energy sector. The Nordic pulp and paper industry is dependent on Nordic forest resources. The demand for paper, especially newsprint, has decreased. Only pulp and paper units that have been converted into bio-refineries make any profits. In summary, the demand for Swedish wood raw materials is high. Annual harvest levels and employment in the forest sector in Sweden are significantly higher than today. Due to continued urbanization, logging camps are set up in remote areas. Forests are managed intensively; rotations have been shortened, while fertilization and fast-growing species, such as hybrid poplar, are being used on a large scale. This development has taken place at the expense of biodiversity and other 
non-wood forest ecosystem services. Forest owners in Sweden have benefited from increased wood prices. The real value of forest land is higher than today.

IV. As in scenario III, in scenario IV globalization has been replaced by regionalism, but climate-change mitigation is much more pronounced. There is also a high degree of environmental concern amongst the public as well as policy-makers. The economic growth is the lowest of all scenarios, and technological progress, centered on the development of bio-energy, is low. Transport and energy costs are the highest of all the scenarios. Global population has stabilized, while the European population is declining and ageing. Urbanization in Sweden and a number of other European countries has halted; in Sweden partly as a result of increasing employment in the forest sector, and partly because an increasing number of people want to live close to nature. Greatly reduced fossil fuel imports and intensive climate-change mitigation have resulted in rapidly growing bio-energy markets. Real prices of forest products have massively increased, as has recycling. Recovered wood and recovered paper are used increasingly for energy, rather than in reconstituted panel and paper production. Since wood imports to the EU have virtually ceased, paired with the high demand for wood for energy purposes, the demand for European wood has increased tremendously. Due to greater emphasis on nature conservation and biodiversity, as well as increased use of forests as carbon sinks, harvest levels in southern and central Europe have not, on average, increased compared to current levels. Mitigation efforts in combination with slow economic growth have led to reductions in GHG emissions, but harvest levels still fluctuate more than today, due to stock effects of climate change. The demand pressure on Swedish wood resources is mounting. Sawmills are prospering, as a result of the combination of elevated demand for energy-efficient, renewable construction materials and rising prices for secondary products, due to expanding bio-energy markets. The wood-based panel industry, on the other hand, is all but gone due to intense competition for its raw materials from the bio-energy and sawmill sectors. The Nordic pulp and paper industry is now dependent on Nordic forest resources; production facilities have not moved to the southern hemisphere. Nevertheless, demand for paper, particularly newsprint, but also printing paper, has decreased compared with today. Only chemical pulp and paper units that have been converted into bio-refineries are surviving. Although there is strong environmental awareness, annual harvest levels in Sweden have increased significantly compared to current levels. Forests exempt from conservation are managed intensively; rotations have been shortened and fast-growing species, such as hybrid poplar, are being used on a large scale. However, forests with low wood-production potential are also managed for non-wood ecosystem services as well as for carbon sequestration. Employment in the Swedish forest sector is much higher than today, due to the elevated demand for wood, reduced mechanization of forest operations, and the growth of non-wood ecosystem services. Forest owners enjoy high wood prices, and the real value of forest land has increased considerably. 


\section{Discussion and Conclusions}

There are factors supporting an increase, as well as a decrease, in the global net demand for wood fiber. The net effect depends on the relative strength of these factors. In general, no future scarcity of wood fiber globally is foreseen. The main factors that could potentially result in global scarcity of wood fiber are continued rapid economic growth in Asia, major calamities such as insect outbreaks, and the development of large-scale bio-energy markets. For the Swedish forest sector, the two most fundamental determinants of wood fiber demand are perhaps degrees to which: (i) current patterns of globalization will continue or be replaced by regionalism, and (ii) concern about the environment, particularly climate change, related policy initiatives and customer preferences, will materialize.

Overall, the outlook for the Swedish solid wood-product industry is optimistic, irrespective of which future occurs; provided it sheds its commodity orientation and increases the value-added by accommodating the growing demand for factory-made, energy-efficient construction components, produced using renewable materials. In addition, the Swedish solid wood-product industry is not facing the same direct threat from globalization as the pulp and paper industry, since the expansion in the southern hemisphere is focused on pulp and paper production. Furthermore, the development of prominent bio-energy markets should mainly benefit the sawmill industry, which should obtain higher prices for secondary products with limited competition from bio-energy markets for raw materials. In the future, integrated production units producing construction components, as well as bio-fuel, bioplastics, and food ingredients, are conceivable. The wood-based panel industry, on the other hand, already of marginal importance in Sweden, would suffer from intense competition for all its raw materials from the bio-energy sector.

The prospects for the pulp and paper industry in Sweden are more difficult to predict. Globalization is increasingly shifting production and consumption to the Southern hemisphere, adversely affecting employment and forest owners (through decreased demand for pulpwood) in Sweden. Further, continued expansion of electronic ICT will most likely result in a significantly reduced demand for newsprint and office paper. Finally, the pulp and paper industry could benefit from, as well as being adversely affected by, the development of a burgeoning bio-energy industry, since chemical pulp producers could manufacture new, high-value products in integrated bio-refineries. Mechanical pulp producers cannot do this, however, and are likely to be affected by higher prices for raw materials and electricity.

Swedish forest owners should benefit from expanding bio-energy markets and resulting higher prices for woody bio-energy feedstocks. Wood fiber for energy purposes can, however, be imported to Sweden from countries with huge biomass potentials, for instance sizeable quantities of wood pellets are imported to Sweden from Canada [88]. The highest demand for Swedish wood fiber, and hence the highest real prices for wood and forest land, can be expected in a regionalized world characterized by considerable public concern regarding global climate change and the environment in general. This possible future is also the one where employment in the forest sector is likely to be the highest of the four considered scenarios.

It is beyond the scope of this paper to give any policy recommendations. However, a few policy issues raised by the scenario analysis will be briefly highlighted. First of all, depending on which future materializes, some tradeoffs will probably be inevitable. Notably, an elevated harvest level and ensuing 
intensified forest management (e.g., shortened rotation periods and fertilization) in Sweden could compromise biodiversity. In particular the general consideration for biodiversity on all productive forest land, a trait of Swedish forest policy, could be at risk. The objective of maximizing wood supply also conflicts to some extent with the objective of increasing carbon sequestration in forests. Another discernible future conflict is between the development of markets for non-wood ecosystem services and public access to forests. Increased flexibility of the forest sector will be needed to cope with both a more fluctuating demand for Swedish wood fibers (resulting from climate change-related forest calamities abroad) and highly variable supply conditions in Sweden.

\section{Acknowledgements}

This study was funded by Future Forests, a Swedish multidisciplinary research program, and its sponsors: the Strategic Foundation for Environmental Research (Mistra), the Swedish University of Agricultural Sciences (SLU), Umeå University, the Forestry Research Institute of Sweden (Skogforsk), and the forest industry in Sweden.

\section{References}

1. Swedish Forest Industries Federation. The Forest Industry-A Natural Part of Sweden; Swedish Forest Industries Federation: Stockholm, Sweden, 2008. Available online: http://www.forestindustries.se/web/Publications_and_surveys.aspx (accessed on 20 September 2010).

2. Swedish Forest Industries Federation. The Swedish Forest Industries-Facts and Figures 2008; Swedish Forest Industries Federation: Stockholm, Sweden, 2009. Available online: http://www.forestindustries.se/web/Publications_and_surveys.aspx (accessed on 23 September 2010).

3. Swedish Forest Industries Federation. Pulp \& Paper Statistics-Fourth Quarter and Total 2009; Swedish Forest Industries Federation: Stockholm, Sweden, 2010. Available online: http://www.forestindustries.se/web/Facts_and_figures.aspx (accessed on 10 October 2010).

4. European Forest Sector Outlook Study: Main Report; United Nations, FAO/UNECE Agriculture and Timber Division, Timber Branch: Geneva, Switzerland, 2005.

5. Kirilenko, A.; Sedjo, R. Climate change impacts on forestry. Proc. Natl. Acad. Sci. USA 2007, 104, 19697-19702.

6. Aulisi, A.; Sauer, A.; Wellington, F. Trees in the Greenhouse-Why Climate Change is Transforming the Forest Products Business; World resources institute: Washington, DC, USA, 2008.

7. State of the World's forests 2009; Food and Agricultural Organization of the United Nations: Rome, Italy, 2009.

8. Solow, R.M. A contribution to the theory of economic growth. Q. J. Econ. 1956, 70, 65-94.

9. Swan, T.W. Economic growth and capital accumulation. Econ. Rec. 1956, 32, 334-361.

10. Rivera-Batiz, L.A.; Romer, P.M. Economic integration and endogenous growth. Q. J. Econ. 1991, 106, 531-555. 
11. Ernst, M.L. Some Implications of Current Social, Economic and Technological Trends; A D Little: Copely Plaza, MA, USA, 1978.

12. Jonsson, R.; Whiteman, A. Global Forest Product Projections; Food and Agricultural Organization of the United Nations: Rome, Italy, in press.

13. European Commission. Key figures 2007: Towards a European Research Area-Science, Technology and Innovation; Commission of the European communities: Brussels, Belgium, 2007.

14. Meier, G.M. Leading Issues in Economic Development, 6th ed.; Oxford University Press: New York, NY, USA, 1995.

15. Cook, C.J. Population growth and savings rates: some new cross-country estimates. Int. Rev. Appl. Econ. 2005, 19, 301-319.

16. World Urbanization Prospects: the 2007 Revision Population Database; United Nations, Department of Economic and Social Affairs, Population Division: New York, NY, USA, 2008. Available online: http://esa.un.org/unup/ (accessed on 11 August 2010).

17. Wohnungsmärkte in Deutschland; Berichte 18; Bundesamt für Bauwesen und Raumordnung: Bonn, Germany, 2004.

18. European Environment Outlook; European Environment Agency: Copenhagen, Denmark, 2005.

19. Munn, I.A.; Barlow, S.A.; Evans, D.L.; Cleaves, D. Urbanization's impact on timber harvesting in the south central United States. J. Environ. Manage. 2002, 64, 65-76.

20. Vickery, B.W.; Germain, R.H.; Bevilacqua, E. Urbanization's impact on sustained yield management as perceived by forestry professionals in central New York. Forest Pol. Econ. 2009, $11,42-49$.

21. Blombäck, P.; Poschen, P.; Lövgren, M. Employment Trends and Prospects in the European Forest Sector; Geneva Timber and Forest Discussion Paper ECE/TIM/DP/14; United Nations: Geneva, Switzerland, 2003.

22. Lindh, T.; Malmberg, B. Demography and Housing Demand-What Can We Learn from Residential Construction Data? Working report 2005:20; The Institute for Futures Studies: Stockholm, Sweden, 2005.

23. Shuler, A.; Adair, C. Demographics, the housing market, and demand for building materials. For. Prod. J. 2003, 53, 8-17.

24. Evans, J.; Turnbull, J. Plantation Forestry in the Tropics, 3rd ed.; Oxford University Press: Oxford, UK, 2004.

25. Whiteman, A. Recent Trends and Developments in Global Markets for Pulp and Paper. Presented at Paperex 2005-International Technical Conference on Pulp and Paper Industry, New Delhi, India, December 2005.

26. van Ree, R.; Annevelink, B. Status Report Biorefinerie 2007; Report 847; Agrotechnology and Food Sciences Group: Wageningen, the Netherlands, 2007. Available online: www.biorefinery.nl/publications (accessed on 3 July 2010).

27. Söderholm, P.; Lundmark, R. The development of forest-based biorefineries: implications for market behavior and policy. For. Prod. J. 2009, 59, 6-16. 
28. Roughley, D.J. Nanotechnology: Implications for the Wood Products Industry. Final Report; Forintek Canada Corporation: North Vancouver, Canada, 2005. Available online: http://www.nanotechbc.ca/resources_/documents/Wood_Products+Nanotech-05.pdf29 (accessed on 9 October 2010).

29. Reitzer, R. Technology Roadmap: Applications of Nanotechnology in the Paper Industry. From the Perspectives of the Nanoscience Center, Market Analysis and Industrial Needs; University of Jyväskylä: Jyväskylä, Finland, 2007.

30. Hetemäki, L.; Obersteiner, M. US Newsprint Demand Forecast to 2020; Interim Report IR-01-070; IIASA: Vienna, Austria, 2001. Available online: http://www.iiasa.ac.at/Publications/ Documents/IR-01-070.pdf (accessed on 8 October 2010).

31. Bolkesjø, T.F.; Solberg, B.; Obersteiner, M. Information technology and the newsprint demand in Western Europe: a Bayesian approach. Can. J. For. Res. 2003, 33, 1644-1652.

32. Hetemäki, L. Information technology and trends in the paper market. Pap. Tim. 2005, 87, 424-427.

33. Hetemäki, L. Information technology and paper demand scenarios. In World Forests, Society and Environment. World Forests; Palo, M., Uusivuori, J., Eds.; Kluwer Academic Publishers: Dordrecht, The Netherlands, 1999.

34. Bael, D; Sedjo, R. Toward Globalization of the Forest Products Industry: Some Trends; Resources for the future discussion paper 06-35; Resources for the future: Washington, DC, USA, 2006.

35. Finnish Forest Industries Federation. Adjusting to Globalization is Vital for the Finnish Pulp and Paper Industries; Finnish Forest Industries Federation: Helsinki, Finland, 2005. Available online: http://www.forestindustries.fi/JuuriNyt/Tiedotteet/Pages/Adjustingtoglobalizationisvitalforthefinni shpulpandpaperindustries.aspx (accessed on 10 September 2010).

36. Jakobsson, U. Globaliseringen och den Svenska Basindustrin-Arbetspapper till Globaliseringsrådet; Government offices of Sweden: Stockholm, Sweden, 2009.

37. Agrell, W. Geopolitics. Competition, Conflicts, and Wars in the Future International System. External Drivers Affecting Swedish Forests and Forestry (Future forests working report); Future Forests: Umeå, Sweden, 2009. Available online: http://www.futureforests.se/program/ futureforests/hem/publikationer/arbetsrapporter.4.5004bd9712b572e3de6800017404.html (accessed on 3 October 2010).

38. Sohngen, B.; Sedjo, R. Impacts of climate change on forest product markets: Implications for North American producers. Forest Chron. 2005, 81, 669-674.

39. Cramer, W.; Bondeau, A.; Woodward, F.I.; Prentice, I.C.; Betts, R.A.; Brovkin, V.; Cox, P.M.; Fisher, V.; Foley, J.A.; Friend, A.D.; Kucharik, C.; Lomas, M.R.; Ramankutty, N.; Sitch, S.; Smith, B.; White, A.; Young-Molling, C. Global response of terrestrial ecosystem structure and function to $\mathrm{CO}_{2}$ and climate change: results from six dynamic global vegetation models. Glob. Change Biol. 2001, 7, 357-373.

40. Solberg, B.; Moiseyev, A.; Kallio, A.M. Economic impacts of accelerating forest growth in Europe. Forest Pol. Econ. 2003, 5, 157-171. 
41. Schroeter, D. ATEAM, Advanced Terrestrial Ecosystem Analysis and Modeling. Final Report; Potsdam Institute for Climate Impact Research: Potsdam, Germany, 2004. Available online: http://www.pik-potsdam.de/ateam/ateam_final_report_sections_5_to_6.pdf (accessed on 12 February 2010).

42. Scholze, M.; Knorr, W.; Arnell, N.W.; Prentice, I.C. A climate-change risk analysis for world ecosystems. Proc. Natl. Acad. Sci. USA 2006, 103, 13116-13120.

43. Sedjo, R. The future of trees: climate change and the timber industry. In Forests and Climate Change; Day, F., Foerster, A., Eds.; Resources for the future: Washington, DC, USA, 2010.

44. Sohngen, B.; Mendelsohn, R.; Sedjo, R. A global model of climate change impacts on timber markets. J. Agric. Resour. Econ. 2001, 26, 326-343.

45. Perez-Garcia, J.; Joyce, L.A.; McGuire, A.D.; Xiao; X. Impacts of climate change on the global forest sector. Clim. Change 2002, 54, 439-461.

46. Sohngen, B.; Mendelsohn, R. An optimal control model of forest carbon sequestration. Am. J. Agric. Econ. 2003, 85, 448-457.

47. IPCC. Fourth Assessment Report: Climate Change 2007: Synthesis Report; Intergovernmental panel on climate change: Geneva, Switzerland, 2007.

48. Hasselmann, K.; Latif M.; Hooss, G.; Azar, C.; Edenhofer, O.; Jaeger, C.C.; Johannessen, O.M.; Kemfert, C.; Welp, M.; Wokaun, A. The challenge of long-term climate change. Science 2003, 302, 1923-1925.

49. Binkley, C.S.; van Kooten, G.C. Integrating climate change and forests: economic and ecological assessments. Clim. Change 1994, 28, 91-110.

50. DCLG. Code for Sustainable Homes: A Step-Change in Sustainable Home Building Practice; Department of Communities and Local Government: London, UK, 2006.

51. European Commission. Proposal for a Directive of the European Parliament and of the Council on the Promotion of the Use of Energy from Renewable Sources; 2008/0016 (COD); Commission of the European communities: Brussels, Belgium, 2008.

52. Peksa-Blanchard, M.; Dolzan, P.; Grassi, A.; Heinimö, J.; Junginger, M.; Ranta, T.; Walter, A. Global Wood Pellets Markets and Industry: Policy Drivers, Market Status and Raw Material Potential; IEA Bioenergy Task 40 report; IEA: Paris, France, 2007. Available online: http://www.bioenergytrade.org/downloads/ieatask40pelletandrawmaterialstudynov2007final.pdf (accessed on 10 August 2010).

53. Engelbrecht, P.-O. Bioenergy and the Forest-based Industries. Presented to the European Legislation to Promote Bioenergy, Brussels, Belgium, November 2006.

54. Roberts, D. Global Vision for the Forest Products Markets and Industry in 2020. Presented at the 2007 International Congress on a Global Vision of Forestry in the 21 st Century, Toronto, Canada, October 2007.

55. Sedjo, R.; Wisniewski, J.; Sample, A.V.; Kinsman, J.D. The economics of managing carbon via forestry: assessment of existing studies. Environ. Resource Econ. 1995, 6, 139-165.

56. Huettl, R.F.; Zoettl, H.W. Forest fertilization: Its potential to increase the $\mathrm{CO}_{2}$ storage capacity and to alleviate the decline of global forests. Water Air Soil Pollut. 1992, 64, 229-250. 
57. Nilsson, L.O. Carbon sequestration in Norway spruce in South Sweden as influenced by air pollution. Water Air Soil Pollut. 1993, 70, 177-186.

58. Hudson, R.; Gherini, S.; Goldstein, R. Modeling the global carbon cycle: Nitrogen fertilization of the terrestrial biosphere and the "missing" $\mathrm{CO}_{2}$ sink. Global Biogeochem. Cy. 1994, 8, 307-333.

59. Oren, R.; Ellsworth, D.S.; Johnsen, K.H.; Phillips, N.; Ewers, B.E.; Maier, C.; Schäfer, K.V.; McCarthy, H.; Hendrey, G.; McNulty, S.G.; Katul, G.G. Soil fertility limits carbon sequestration by forest ecosystems in a $\mathrm{CO}_{2}$-enriched atmosphere. Nature 2001, 411, 469-472.

60. Hoehn, H.F; Solberg, B. Potential and economic efficiency of carbon sequestration in forest biomass through silvicultural management. For. Sci. 1994, 40, 429-451.

61. van Kooten, G.C.; Binkley, C.S.; Delcourt, G. Effect of carbon taxes and subsidies on optimal forest rotation age and supply of carbon services. Am. J. Agric. Econ. 1995, 77, 365-374.

62. Backéus, S.; Wikström, P.; Lämås, T. A model for regional analysis of carbon sequestration. For. Ecol. Manage. 2005, 216, 28-40.

63. Sedjo, R. Forest Carbon Sequestration: Some Issues for Forest Investments; Discussion Paper 01-34; Resources for the Future: Washington, DC, USA, 2001.

64. Newell, R.G.; Stavins, R.N. Climate change and forest sinks: factors affecting the costs of carbon sequestration. J. Environ. Econ. Manage. 2000, 40, 211-235.

65. Frühwald, A.; Welling, J.; Scharai-Rad, M. 2003. Comparison of Wood Products and Major Substitutes with Respect to Environmental and Energy Balances. In Proceeding of the Seminar Strategies for the Sound Use of Wood, Poiana Brasov, Romania, March 2003; pp. 149-160.

66. Thoroe, C.; Peck, T.; Guarin Corredor, H.; Schmithüsen, F. The Policy Context of the European Forest Sector; Geneva Timber and Forest Discussion Paper ECE/TIM/DP/34; United Nations: Geneva, Switzerland, 2004.

67. Rametsteiner, E.; Kraxner, F. Europeans and Their Forests: What do Europeans Think about Forests and Sustainable Forest Management? MCPFE Liaison Unit: Vienna, Austria, 2003.

68. Nationale Strategie zur Biologischen Vielfalt; Referat Öffentlichkeitsarbeit; Bundesministerium für Umwelt, Naturschutz und Reaktorsicherheit (BMU): Berlin, Germany, 2007.

69. Verkerk, P.J.; Zanchi, G.; Lindner, M. Impacts of Biological and Landscape Diversity Protection on the Wood Supply in Europe; EFI Technical Report 27; European Forest Institute: Joensuu, Finland, 2008.

70. Glenn, J.C. Introduction to the futures research methodology series. In Futures Research Methodology; Glenn, J.C., Ed.; American Council for the United Nations University: Washington, DC, USA, 1999.

71. Cornish, E. Futuring: The Exploration of the Future; World Future Society: Bethesda, MD, USA, 2004.

72. Duinker, P.N.; Greig, L.A. Scenario analysis in environmental impact assessment: improving explorations of the future. Environ. Impact Assess. Rev. 2007, 27, 206-219.

73. Bjil, R. Delphi in a future scenario study on mental health and mental health care. Futures 1992, 24, 232-250.

74. Skumanich, M.; Silbernagel, M. Foresighting around the World; Battelle Seattle Research Center: Seattle, WA, USA, 1997. 
75. Duinker P.N.; Baskerville, G.L. A systematic approach to forecasting in environmental impact assessment. J. Environ. Manage. 1986, 23, 271-290.

76. Kaivo-oja, J. Scenario learning and potential sustainable development processes in spatial contexts: towards risk society or ecological modernization scenarios? Futures Res. Q. 2001, 17, 33-55.

77. Ono, R.; Wedemeyer, D. Assessing the validity of the Delphi technique. Futures 1994, 26, 289-304.

78. Webler, T.; Levine, D.; Rakel, H.; Renn, O. A novel approach to reducing uncertainty: the group Delphi. Technol. Forecast Soc. Change 1991, 39, 253-263.

79. Raskin, P.; Kemp-Benedict, E. Global Environment Outlook Scenario Framework: Background Paper for UNEP's Third Global Environment Outlook Report (GEO-3); United Nations Environment Programme (UNEP): Nairobi, Kenya, 2004.

80. van der Heijden, K. Scenarios: The Art of Strategic Conversation; Wiley: New York, NY, USA, 1996.

81. Raskin, P.; Gallopin, G.; Gutman, P.; Hammond, A.; Swart, R. Bending the Curve: Toward Global Sustainability; Stockholm Environment Institute: Stockholm, Sweden, 1998.

82. Postma, T.J..; Liebl, F. How to improve scenario analysis as a strategic management tool? Technol. Forecast Soc. Change 2005, 72, 161-173.

83. Greeuw, S.C.; van Asselt, M.B ; Grosskurth, J.; Storms, C.A.; Rijkens-Klomp, N.; Rothman, D.S.; Rotmans, J. Cloudy Crystal Balls: An Assessment of Recent European and Global Scenario Studies and Models; Environmental Issue Report no. 17; European Environment Agency: Copenhagen, Denmark, 2000.

84. Schwartz, P. The Art of the Long View: Planning for the Future in an Uncertain World; Currency Doubleday: New York, NY, USA, 1996.

85. Porter, M.E. Competitive Advantage-Creating and Sustaining Superior Performance; Free Press: New York, NY, USA, 1985.

86. Schoemaker, P.J.H. Twenty common pitfalls in scenario planning. In Learning from the Scenarios: Competitive Foresight Scenarios; Fahley, L., Radall, R.M., Eds.; John Wiley and Sons: New York, NY, USA, 1998.

87. Godet, M. The art of scenarios and strategic planning: Tools and pitfalls. Technol Forecast Soc. Change 2000, 65, 3-22.

88. Junginger, M.; Bolkesjø, T.; Bradley, D.; Dolzan, P.; Faaij, A.; Heinimö, J.; Hektor, B.; Leistad, Ø.; Ling, E.; Perry, M.; Piacente, E.; Rosillo-Calle, F.; Ryckmans, Y.; Schouwenberg, P.-P.; Solberg, B.; Trømborg, E.; da Silva Walter, A.; de Wit, M. Developments in international bio-energy trade. Biomass Bioenerg. 2008, 32, 717-729.

(C) 2011 by the authors; licensee MDPI, Basel, Switzerland. This article is an open access article distributed under the terms and conditions of the Creative Commons Attribution license (http://creativecommons.org/licenses/by/3.0/). 